\title{
Common Viper Bites in the Czech Republic - Epidemiological and Clinical Aspects during 15 Year Period (1999-2013)
}

\author{
Jiří Valenta, Zdeněk Stach, Martin Stříteský, Pavel Michálek \\ Department of Anesthesiology and Intensive Care, First Faculty of Medicine, \\ Charles University in Prague and General University Hospital in Prague, Prague, \\ Czech Republic
}

Received August 28, 2014; Accepted November 18, 2014.

Key words: Snakebite - Vipera berus - Envenoming - Epidemiology - Antivenom

Abstract: The aim of this study was to analyse most important epidemiological and clinical aspects of registered snakebites caused by a native common European viper Vipera berus in the Czech Republic over a period of 15 years (1999-2013).

Data have been collected retrospectively from a database of the Toxinology Centre belonging to the General University Hospital in Prague. In total, 191 cases of snakebites caused by common viper were registered during the study period. Systemic envenoming occurred in 49 (25.7\%) patients, local envenoming without systemic symptoms was recorded in $91(47.6 \%)$ and asymptomatic dry bites were seen in 51 (26.7\%) cases, respectively. Twenty-four patients (12.6\% of all bites) were treated with administration of antivenom. None of the victims died as a result of snakebite during the observation period. Native viper snakes usually did not cause serious harm to the patients, with the exception of children. Antivenom should be administered in all cases with systemic manifestations, in children even with serious local affection and administered as soon as possible. Envenomed patients should be admitted to the hospital and treated at least under supervision of specialists with experience in snakebite treatment, who can indicate and provide administration of the antivenom.

Mailing Address: Jiř́ Valenta, MD., Department of Anesthesiology and Intensive Care, First Faculty of Medicine, Charles University in Prague and General University Hospital in Prague, U Nemocnice 2, 12808 Prague 2, Czech Republic; e-mail: valenta@vfn.cz 


\section{Introduction}

The common European viper Vipera berus is native snake to nearly whole Europe, with an exemption of some southern areas. In Middle, West, North, Northwest and Northeast Europe, this is the only venomous snake. Snakebites caused by this viper do not have high epidemiological importance and in most cases are not associated with a serious clinical symptomatology and this envenoming is not life-threatening (Reid, 1976; Persson, 1995). However, children may develop extensive swelling and/or severe systemic symptoms of envenoming.

Snakebites caused by the common viper and even exotic venomous snakes are very rare in European countries and therefore their medical management is outside of standard medical experience. In the Czech Republic (CR), as well as in other European countries, the snakebites caused by native common viper occur during outdoor activities while the bites caused by exotic venomous snakes happen during handling of snakes and manipulations in the terrarium.

Therefore the Toxinology Centre (TC) coordinating and treating all cases of animal envenomings was established in 1993.TC is a part of the Department of Anesthesiology and Intensive Care of the First Faculty of Medicine affiliated to the Charles University and General University Hospital in Prague and provides medical consulting services for other health facilities in cases of snakebite, as well as hospital admission and treatment for seriously envenomed victims. The TC covers the area of entire CR. The health facilities are not legally obliged to refer the envenomings; however, they mostly contact the TC. The centre is always consulted in severe cases of envenoming and in all envenomings caused by the exotic snakes (Valenta et al., 2014).

\section{Contacts}

Indication of antivenom treatment a consultation of the therapy Toxinology Centre, Department of Anesthesiology and Intensive Care, First Faculty of Medicine, Charles University in Prague and General University Hospital in Prague, Prague. Phone No.: +420 224963 355, web: www.karim-vfn.cz.

Storage of Vipera berus antivenom (Vipera TAb, MicroPharm, UK) Toxicological Information Centre, Department of Occupational Medicine, First Faculty of Medicine, Charles University in Prague, Prague. Phone Nos.: +420 224919 293, +420224915402.

The main objective of this study was to evaluate the incidence and principal clinical and epidemiological aspects of snakebites caused by the native common viper Vipera berus in the CR over a period of last fifteen years.

\section{Material and Methods}

This retrospective study was completed through a review of the medical charts and database of patients affected by snakebites, which were consulted or treated 
under consultation of our TC, over a period of 15 years (from January 1999 until December 2013). Data were collected from the TC database and medical charts from other health facilities. The cohort included cases where advice was sought from the TC but also those cases that were treated in other medical facilities.

The following parameters were analysed in patients affected by the native viper bites - clinical signs and symptoms, gender, month of the year (seasonal prevalence) and distribution area of Vipera berus bites. Snakebites were always confirmed with a local finding (typical shape of the snakebite) and, in most cases, also by identification of the snake. These examinations helped to exclude non-venomous snakebites, which are not accompanied by a characteristic signs of fang-bites.

The term local envenoming was used to describe local affection of varying severity, from local swelling to extensive swelling, without any systemic signs of envenoming. Systemic envenoming meant both clinical or laboratory findings indicating systemic impacts due to a venom. These symptoms included nausea, vomiting, abdominal cramps, diarrhoea, and hypotension. Typical laboratory findings were elevation in white blood cells; limit for systemic envenoming is more than $20 \times 10^{9} / l$ (Persson, 1995).

Hospital admissions, either for observation only or for treatment, including antivenom administration, were recorded.

\section{Results}

A total number of 191 cases of the Vipera berus bites (average 12.7 per year) were recorded over the study period. This cohort involved 92 males, 53 females and 46 children aged 4-15 years. Fifty-one (26.7\%) cases were considered as asymptomatic dry bites, while 91 (47.6\%) cases were local envenoming only, without systemic symptoms, and $49(25.7 \%)$ patients developed systemic envenomings. The mean incidence of both local and systemic envenoming was 9.3 per year. The mean annual incidence of bites and envenoming was 0.12 and 0.09 per 100000 inhabitants, respectively (the entire population of the Czech Republic is 10.5 million).

Regarding local envenoming, in total 91 patients experienced following symptoms: local pain, erythema, localized swelling including haemorrhagic or extended oedema or regional lymph node reaction. This group included also 3 cases of extensive and haemorrhagic oedema in children without a systemic reaction. These cases are included in "local envenoming only" group (Table 1). Moderate systemic envenoming (local symptomatology, mild hypotension, vomiting, and diarrhoea) was recorded in 46 cases (24.1\%) (Table 1). More serious systemic reaction with above described symptomatology including hypotension with indication for volume replacement therapy was observed in 3 cases of systemic envenoming and in 3 children with an extensive limb oedema with a trunk spread (mentioned above as local envenoming). This can be characterized as severe envenoming as well. All envenomings caused by $V$. berus were treated in other hospitals under TC phone supervision. TC physician indicated antivenom administration, provided its supply 
(in majority of envenomings) and observed the course of treatment including outcome.

Antivenoms (formerly Sanofi Pasteur Ipser Europe, France; Biomed Antitoxin, Poland; recently Vipera TAb MicroPharm, UK) were used in 24 cases (12.6\% of all bites), predominantly in paediatric patients (Table 1). An antihistamine premedication (hydrocortisone, bisulepine) was routinely used before antivenom administration.

Indications for antivenom application were based on published evidence (Reid, 1976; Persson and Irestedt, 1981; Cederholm and Lennmarken, 1987; Persson, 1995) and used in our cases mostly in the presence of systemic symptoms such as gastrointestinal disturbances and hypotension. The antiserum Vipera TAb was administered in three children with local manifestation of envenoming associated with extensive limb swelling (Kleber and Zilker, 1998). No allergic reaction during antivenom treatment was observed.

In our cohort, snakebites caused by the $V$. berus presented in a similar manner as previously described clinical course of this envenoming. We did not record any unusual clinical symptoms or complications during the study period. We did not register also any neurological symptomatology, which is sometimes described in connection with this type of envenoming. Anaphylactic reaction was observed in two patients. In the first case, anaphylaxis occurred concurrently with clinical symptoms of envenoming (nausea and vomiting - an envenomed woman in Table 1), in the second case we observed isolated anaphylactic reaction (a child with systemic reaction in Table 1).

Table 1 - Common European viper bites in the Czech Republic 1999-2013

\begin{tabular}{|c|c|c|c|c|c|c|c|c|}
\hline & \multicolumn{2}{|c|}{ Viper bites } & \multicolumn{2}{|c|}{ Dry bites } & \multicolumn{2}{|c|}{$\begin{array}{l}\text { Local } \\
\text { envenoming only }\end{array}$} & \multicolumn{2}{|c|}{$\begin{array}{c}\text { Systemic } \\
\text { envenoming }\end{array}$} \\
\hline & $\mathrm{n}$ & $\%$ & $\mathrm{n}$ & $\%$ & $\mathrm{n}$ & $\%$ & $\mathrm{n}$ & $\%$ \\
\hline Total & 191 & 100.0 & 51 & 26.7 & 91 & 47.6 & 49 & 25.7 \\
\hline Male & 92 & 48.2 & 24 & 12.6 & 44 & 23.0 & 24 & 12.6 \\
\hline Female & 53 & 27.7 & 18 & 9.4 & 19 & 9.9 & 16 & 8.4 \\
\hline \multirow[t]{3}{*}{ Children } & 46 & 24.1 & 9 & 4.7 & 28 & 14.7 & 9 & 4.7 \\
\hline & \multicolumn{2}{|c|}{$\begin{array}{c}\text { Hospital admission } \\
\text { observation }\end{array}$} & \multicolumn{2}{|c|}{$\begin{array}{c}\text { Hospital admission } \\
\text { treatment }\end{array}$} & \multicolumn{2}{|c|}{$\begin{array}{c}\text { Hospital admission } \\
\text { total }\end{array}$} & \multicolumn{2}{|c|}{$\begin{array}{l}\text { Antivenom } \\
\text { treatment }\end{array}$} \\
\hline & $\mathrm{n}$ & $\%$ & $\mathrm{n}$ & $\%$ & $\mathrm{n}$ & $\%$ & $\mathrm{n}$ & $\%$ \\
\hline Total & 52 & 27.2 & 52 & 27.2 & 104 & 54.5 & 24 & 12.6 \\
\hline Male & 17 & 8.9 & 23 & 12.0 & 40 & 20.9 & 7 & 3.7 \\
\hline Female & 11 & 5.8 & 15 & 7.9 & 26 & 13.6 & 6 & 3.1 \\
\hline Children & 24 & 12.6 & 14 & 7.3 & 38 & 19.9 & 11 & 5.8 \\
\hline
\end{tabular}


Most cases of bites were reported in geographical areas with increased appearance of the common European viper as confirmed by herpetological investigations (Voženílek, 2000). In fact, the areas of incidence were rather related to the hospital network visited by victims (Figure 1). The bites usually occurred from March to October with a maximum in July (Figure 2).

No death associated with snakebite was registered in the Czech Republic during this 15 year period (1999-2013).

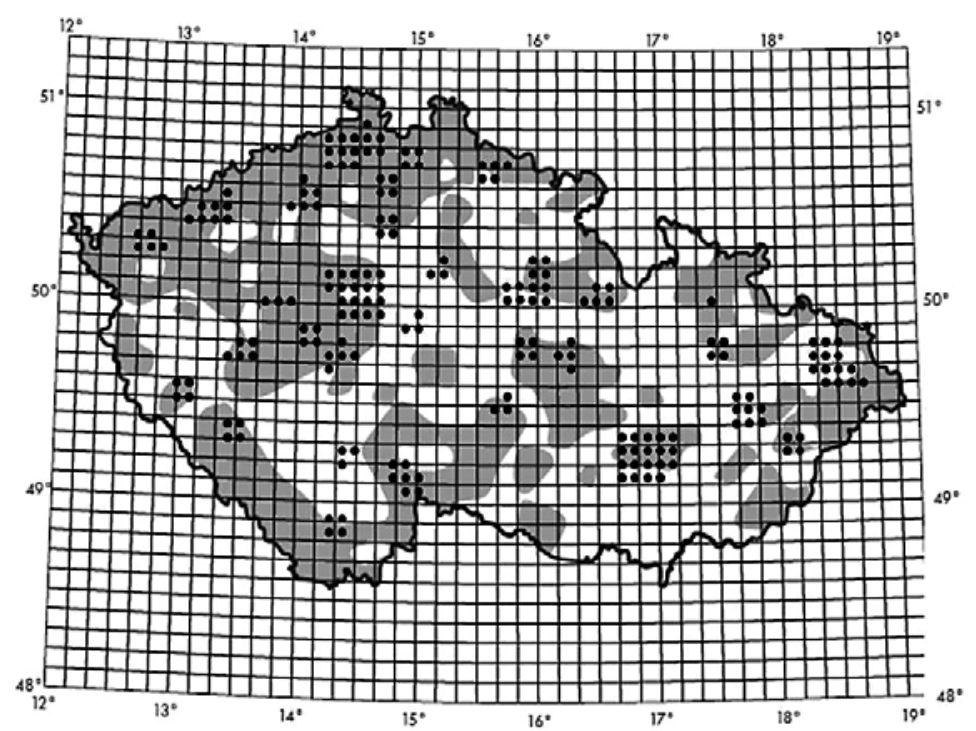

Figure 1 - Main Vipera berus localities (shaded areas) as confirmed by herpetological investigation (Voženilek, 2000) and occurrence of 191 viper bites (black points) in the Czech Republic 1999-2013.

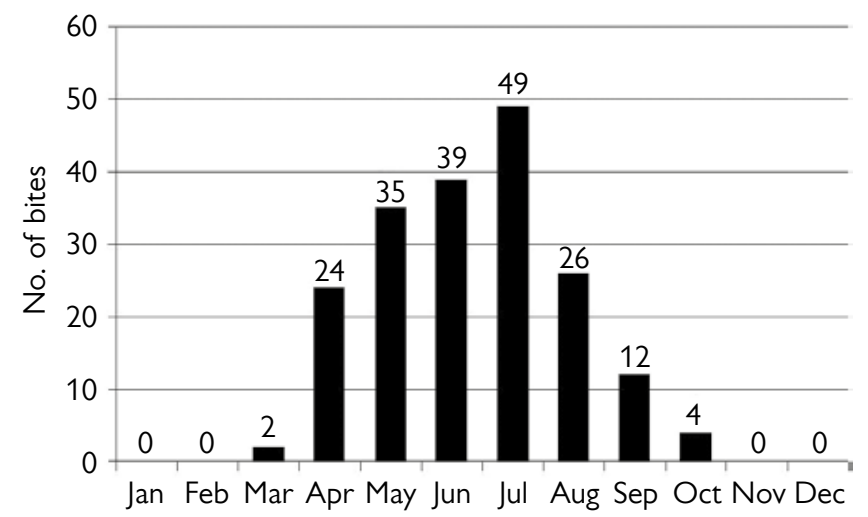

Figure 2 - Seasonal prevalence of Vipera berus bites in the Czech Republic 1999-2013. 


\section{Discussion}

The number of native viper snakebites registered by TC was 191 over 15 years, with morbidity including local findings 140 over 15 years (73.3\%). This corresponds to an annual incidence of $0.12 / 100000$ and $0.09 / 100000$ inhabitants, respectively. Since we assume that not all snakebites were reported to the TC, it is very likely that their real incidence is higher, mainly in terms of asymptomatic dry bites and mild local symptomatology. Some European statistics show a high variability of snakebite incidence. In Hungary, recorded incidence is only $0.0047 / 100000$ (Malina et al., 2008), in the United Kingdom 0.2/100 000 (Reading, 1996), in Italy 0.38/100 000 (Pozio, 1998) and 0.82/100 000 (Barelli et al., 2002) respectively, whilst in Sweden it is 2.6/100 000 (Karlson-Stiber et al., 2006) and in Southern Croatia 5.2/100 000 inhabitants (Luksic et al., 2006). Annual adjusted incidence in France is reported from 0.51 to $3.35 / 100000$ (Chippaux, 2012). A similar incidence of snakebite to that in our cohort occurs in the Croatian North Dalmatia region: 93 in 10 years (Karlo et al., 2011). Differences between the countries are not reasonably explained merely by varying occurrence of vipers and population density in rural areas, but they are also related to the methodology of snakebite reporting and statistical processing. The overall annual adjusted incidence of native viper snakebites in central Europe is $1.02 / 100000$, whereas for the whole of Europe it is 1.06/100 000 inhabitants (Chippaux, 2012).

The prevalence of asymptomatic dry bites, $26.7 \%$ in the Czech Republic, is significantly higher than reported numbers for central Europe - 11\% (Chippaux, 2012), which may be explained by a different system of reporting.

The severity of native viper bite envenomings was quite low in our group. Their clinical manifestations were only mild hypotension and gastrointestinal symptoms. The occurrence of isolated tachycardia was not always related to envenoming; it could be caused only by psychogenic factors.

Local findings included swelling, petechiae, ecchymoses and lymphadenopathy, apart from three paediatric patients where extensive oedema developed. Application of antivenom Vipera TAb helped to terminate expansion of oedema in these cases. We consider such types of envenoming in children as serious and the use of antivenom is indicated. Observed mild courses of envenoming in our cohort could be explained by the early treatment of clinical symptoms - hospital admission, symptomatic therapy (volume replacement therapy, antiemetics etc.) and by rapid antivenom treatment in all cases of systemic envenoming (Warrell, 2005).

Although the possibility of allergic reaction during and after antivenom administration is reported in the literature (Malasit et al., 1986), no such allergic reaction developed in our patients. This can be explained by the use of fewer vials than reported in the literature, with repeated administration when required and by strict use of antihistamine and steroid premedication.

It may be assumed that all snakebites with severe envenoming were treated in or referred to the TC. Certainly, not all cases of dry bites and mild forms of 
envenoming were reported or referred. The prevalence of recorded snakebites is therefore probably lower than in reality. Nevertheless all cases of more serious envenoming were either consulted or treated under TC supervision. Although bites caused by venomous snakes do not cause epidemiologically serious problems in the CR, it is useful to register these cases and treat them effectively, ideally in designated medical facilities. This protocol can prevent severe morbidity or even death of the envenomed victims.

\section{Conclusion}

The incidence of registered snakebites in the CR caused by native Vipera berus and its morbidity is $0.12 / 100000$ and $0.09 / 100000$ respectively. The envenoming is not usually associated with serious harm to the patients with the exception of children.

Antivenom should be used in any snakebite with systemic manifestation, in children even when a serious local affection is present, and administered as soon as possible. Envenomed patients should be admitted to the hospital and treated at least under supervision of specialists with experience in snakebite treatment, who can indicate and provide delivery of the antivenom.

Under the compliance with the above mentioned recommendations, we did not experience any serious or even lethal course of native viper snakebite envenoming in the CR during the study period.

\section{References}

Barelli, A., De Giacomo, M., Russo, A., Gargano, F., Dannaoui, B., Della Puppa, T., Assisi, F. (2002) Snake envenomation: Is it a European toxicological problem? J. Toxicol. Clin. Toxicol. 40, 304-306.

Cederholm, I., Lennmarken, C. (1987) Vipera berus bites in children - Experience of early antivenom treatment. Acta Paediatr. Scand. 76, 682-684.

Chippaux, J. P. (2012) Epidemiology of snakebites in Europe: A systemic review of the literature. Toxicon 59, 86-99.

Karlo, R., Dzelalija, B., Zupancic, B., Bacic, I., Dunatov, T., Kanjer, A., Skarica, R., Sabalic, S., Bukvic, N., Nikolic, H., Augustin, G. (2011) Venomous snakebites in the Croatian North Dalmatia region. Wien. Klin. Wochenschr. 123, 732-737.

Karlson-Stiber, C., Salmonson, H., Persson, H. (2006) A nationwide study of Vipera berus bites during one year-epidemiology and morbidity of 231 cases. Clin. Toxicol. 44, 25-30.

Kleber, J. J., Zilker, T. (1998) Adder bites in humans. Tierarztl. Prax. Ausg. K Kleintiere Heimtiere 26, 95-100.

Luksic, B., Bradaric, N., Prgomet, S. (2006) Venomous snakebites in Southern Croatia. Coll. Antropol. 30, 191-197.

Malasit, P., Warrell, D. A., Chanthavanich, P., Viravan, C., Mongkolsapaya, J., Singhthong, B., Supich, C. (1986) Prediction, prevention and mechanism of early (anaphylactic) antivenom reactions in victims of snakebites. Br. Med. J. 292, 17-20.

Malina, T., Krescsak, L., Korsos, Z., Takacs, Z. (2008) Snakebites in Hungary - Epidemiological and clinical aspect over the past 36 years. Toxicon 51, 943-951.

Persson, H. (1995) Clinical toxicology of snakebite in Europe. In: Clinical Toxicology of Venoms and Poisons, eds. Meier, J., White, J., pp. 413-432, CRC Press, Boca Raton. 
Persson, H., Irestedt, B. (1981) A study of 136 cases of adder bite treated in Swedish hospital during one year. Acta Med. Scand. 210, 433-439.

Pozio, E. (1988) Venomous snake bites in Italy: Epidemiological and clinical aspects. Trop. Med. Parasitol. 39, 62-66.

Reading, C. J. (1996) Incidence, pathology, and treatment of adder (Vipera berus L.) bites in man. J. Accid. Emerg. Med. 13, 346-351.

Reid, H. A. (1976) Adder bites in Britain. Br. Med. J. 2, 153-156.

Valenta, J., Stach, Z., Michalek, P. (2014) Exotic snake bites in the Czech Republic - Epidemiological and clinical aspects during 15-year period (1999-2013). Clin. Toxicol. 52, 258-264.

Voženílek, P. (2000) Ty Zmije (The Vipers). Ministry of the Environment of the Czech Republic, Prague. (in Czech)

Warrell, D. A. (2005) Treatment of bites by adders and exotic venomous snakes. Br. Med. J. 331, 1244-1247. 